\title{
De la cultura de la vulgaridad a la ética de la virtud: esbozo de una vida virtuosa
}

From the culture of vulgarity to virtue ethics: An outline of a virtuous life

\author{
Roger V. Yajure Revilla* \\ Facultad de Ciencias de la Comunicación, Turismo y Psicología, \\ Universidad de San Martín de Porres, Perú
}

\section{Resumen}

Hacer un esbozo para entender cómo se logra una vida virtuosa puede parecer un exceso de grandeza. Nuestro artículo, no pretende dejar todo definido, sino introducirnos en la realidad ética de nuestro mundo actual, mediante el análisis y presentación de algunas características de lo que sucede hoy en día. Teniendo como método la reflexión filosófica, partiremos de estudiar el relativismo por medio de la manifestación de su cara mas visible: la cultura de la vulgaridad y el individualismo. Primero, analizaremos nuestra propia idea de la filosofía y cómo ha evolucionado a lo largo del tiempo; luego, desarrollaremos lo que es la ética de la virtud, o como bien lo hemos denominado en clases: el humanismo del amor. Este trabajo, es a la vez, una consecuencia lógica de intentar exponer a nuestros alumnos las ideas axiales de pensamiento, expresadas por Juan Leuridan en su obra El sentido de las dimensiones éticas de la vida.

Palabras clave: cultura; filosofía; virtud; posmoderna(o); vulgaridad; individualismo; modernidad 


\begin{abstract}
Making an outline to understand how a virtuous life is achieved may seem like an excess of greatness. Our article is not intended to leave everything defined, but to introduce us to the ethical reality of our current world through the analysis and presentation of some characteristics of what is happening today. Using the philosophical reflection as a method, we will start to study relativism by showing its most visible face: the culture of vulgarity and individualism. First, we will analyze our own idea of philosophy and how it has evolved over time. Finally, we will sketch, as in a picture, the lines of what virtue ethics is or, as we have called it in class, the humanism of love. This work is, at the same time, a logical consequence of trying to present to our students the axial ideas of thought expressed by J. Leuridan in his work on the meaning of the ethical dimensions of life.
\end{abstract}

Keywords: culture; philosophy; virtue; postmodern; vulgarity; individualism; modernity

\title{
La cultura de la vulgaridad
}

A manera de introducción, nos toca analizar la problemática contemporánea en la que nos encontramos al tratar de estudiar de manera minuciosa nuestra realidad actual desde el enfoque de la ética, teniendo como forma de trabajo el método filosófico. Desde nuestra humilde cátedra, abordamos este tema basándonos en las reflexiones propuestas que aparecen a lo largo de la obra del doctor Johan Leuridan Huys: El sentido de las dimensiones éticas de la vida.

Al iniciar cualquier estudio de filosofía, debemos partir de tener una idea sobre lo que es y no es la filosofía. Partamos de lo que no es. No se trata de una ciencia que busca solo formular preguntas o dar respuestas únicas a problemas tan diversos como el problema del mal o el origen del universo. Se trata de, como decía Sócrates, buscar el saber la verdad, pero como una forma de vivir. 
En tal sentido, la filosofía no es solo una ciencia, que en lenguaje actual busca leyes para predecir posibles hechos. No, la filosofía es un saber para gustar de la vida, la buena vida. Es ahí donde entra el otro aspecto de este curso: la ética.

No pienses, estimado lector, que hemos venido aquí para dar respuestas a las injusticias políticas o los grandes problemas éticos y morales de la actualidad, te equivocas. Esta lectura, este saber, creo que más que dar respuestas, lo que busca es originar que veamos a la realidad con nuevas inquietudes. Recuerdo que un alumno me comentaba que luego de haber estado en clases, cuando iba al cine o veía una película, se daba cuenta de que ya no la veía como antes, quería saber cuál era la visión del cineasta sobre la vida, el amor o el propio mundo. Lo curioso es que el alumno decía que eso era mi culpa. Resulta que yo utilizo videos, musicales, tráileres de películas y audios para hacer la introducción a las lecciones, y esto le marcó su vida. Desde mi punto de vista, la filosofía no es para enseñarte a pensar. Eso ya lo haces, es para repensar o mejor ver el mundo desde otra óptica.

Leía a M. Sandel, en su obra Justicia, y este comentaba que en el mundo actual, de los algoritmos y el positivismo, ver las cosas con ojos de niño, y con asombro, quizás sea lo que la humanidad ha perdido. No solo hemos perdido nuestra inocencia, sino ese asombro con el cual todo en la vida tiene un sentido. De eso se trata este análisis de ver a la filosofía, al mundo y la ética, con ojos de asombro. Para quizás entendernos a nosotros como parte del todo (Sandel, 2012).

\section{Los problemas éticos hoy: escepticismo, posmodernidad y cultura de la vulgaridad}

Siempre debemos partir o tener un punto de partida, el cual nos va a indicar que estamos bien o mal ubicados. Nuestro punto o método será histórico. Empezamos con un personaje: Christophorus Cellarius, o Cristóbal Cellarius, (1638-1707, en alemán: Cristoph Keller), fue un historiador alemán y profesor de Retórica e Historia en la Universidad de Halle. Aunque este dato incluso no parece relevante o aunque no hayas oído hablar de él. Lo más seguro es que recuerdes que podemos dividir la historia de la humanidad en varias etapas, ¿recuerdas?: Antigua, Media y Moderna. Los expertos señalan que es gracias a este historiador que debemos ese análisis. Esto es importante, 
pues para algunos también podemos usar este método para entender de manera inicial como ha ido evolucionando la filosofía.

Siguiendo este esquema podríamos ampliar y afirmar que actualmente y a partir de finales del siglo XIX hemos entrado en lo que se denomina la época posmoderna.

\section{Los primeros filósofos: la filosofía antigua}

Pero, cómo era la filosofía al inicio. Lo primero que hay que afirmar es que la filosofía no nace en universidades o escuelas, como algunos hoy pueden pensar (Leuridan, 2018). Nace en las calles, pero dentro de una cultura muy específica, la cultura griega en la antigüedad. Nace de la mano de pensadores como Sócrates, Platón o Aristóteles. De una manera general, podríamos decir que surge del asombro. El asombro del hombre frente a lo que hay, a lo que le rodea. Si algo tuvieron en común los filósofos de la edad media, fue el entender la filosofía como un saber. Pero no un saber al estilo de ahora, abstracto o teórico. Se trataba de un saber para vivir.

La mayoría de nuestros pensadores y filósofos antiguos llegaron, por medio de la observación y reflexión sobre el mundo, a postular que todo lo que existe forma parte de un algo esencial. Un primer principio, un arjé, o arche. Por otro lado, casi como siguiendo la línea de la compresión mítica, pero desde un punto de vista racional, los filósofos antiguos se ven a sí mismos y todo lo que existe como parte de un todo, del cual y en armonía todos forman parte.

La palabra para esto es cosmos que define el universo de todo lo creado como un orden. En oposición al caos. Empezando por los filósofos presocráticos, como Tales de Mileto. Se creía que había un elemento que lo formaba todo. Él afirmaba que este era el agua. Pero en su misma escuela Anaxímenes, llego afirmar que era el aire. Por su parte Heráclito, creyó que era el fuego, pero a su vez lo afirmaba porque el fuego poseía una especie de movimiento perenne. Este filósofo fue el que afirmo que lo único que permanece es el movimiento: panta rei, todo fluye. Todos ellos tenían en común hablar de un solo elemento un arjé único. Sin embargo, hubo unos que pensaron en una especie de pluralidad de elementos: tierra, aire, agua y fuego. Está de más decir que hasta el día de hoy hablamos de los famosos 
cuatro elementos de la alquimia. Si no me creen consulten o pregunten a alguien por su signo y su elemento zodiacal. En fin, avancemos.

\section{Los filósofos medievales: la filosofía medieval}

Luego de la irrupción del cristianismo en el mundo romano, quienes fueron los herederos de la filosofía y pensamiento heleno, la filosofía adquiere una nueva forma de ver la realidad y de verse a sí misma. Ahora la filosofía se hace desde las inquietudes de la fe. La religión judeocristiana en un inicio y la cristiana al final de esta época, ponen en el ruedo una nueva forma de ver y de entenderse del hombre.

Él se vera a sí mismo, ya no como parte de un cosmos, sino como un ser creado. El cristianismo, primero se servirá de la filosofía como apología, luego se servirá de ella como teología, hasta que esta última adquiera su mayoría de edad como ciencia de la revelación. Para esta reflexión, basta entender que durante esta época la visión cristiana es la base de todo el discurso filosófico. De esta forma la filosofía se vuelve teocéntrica.

Dos grandes hitos se dieron en la filosofía de este tiempo, primero y de la mano de los que después recibieron el nombre de Santos Padres de la Iglesia, nace lo que se conoce como patrística y luego de la mano de su principal propulsor Tomás de Aquino, la escolástica. Estos filósofos y a la vez teólogos han marcado la ruta de la filosofía cristiana, hasta hoy.

\section{Los filósofos modernos: la filosofía moderna}

Si la fe es la orientación básica de la filosofía medieval, en esta época será la razón. A partir de R. Descartes (1596-1650), a quien se le conoce como padre de la filosofía moderna, nace una nueva forma de ver y de hacer filosofía. La cual ya no busca nada al externo del hombre para explicarse a sí mismo. Cartesius con su duda metódica inaugura una nueva época. Su punto de partida no será una base o principio de autoridad ajena al hombre para explicar el todo, sino la duda. El cuestionar incluso la propia autoridad de su época. El parte de la idea de que el hombre con su sola razón puede alcanzar la comprensión del todo. Se abandona, afirma Leuridan (2016), las seguridades del todo para entrar en la duda. 
Las primeras grandes figuras que expresan el cambio son Hobbes y Locke, bajo la influencia del francés Descartes que planteó la autonomía de la razón frente a la fe: «pienso luego existo» y «la única seguridad es la duda». Los teólogos ingleses como John Tillotson (1630-1694) y Matthew Tindal (1656-1733), que preferían la razón a la fe en la interpretación de la Biblia, llamaban a Descartes «The Unparallelled. (Leuridan, 2018, p. 5)

De esta forma se pasa de hacer una filosofía basada en la fe «teocéntrica», a una filosofía basada en el hombre y su sola razón, lo que en griego podríamos llamar, filosofía «antropocéntrica». Una filosofía que tuvo y tiene sus méritos, como el resurgir de la democracia, desde el punto de vista político, y que dio paso a la nuevas ciencias y tecnologías, y grandes invenciones humanas. Que quizás desde el punto de vista de la Ilustración tuvo su punto más álgido en el tema de la dignidad humana con la Declaración de los Derechos:

La tradición judeo-cristiana ha dado dignidad a todos, independientemente de sus talentos, estatus social o juicios humanos. Todos los hombres tienen valor intrínseco porque Dios los ha creado. El hombre está hecho a la imagen de Dios (Mateo, 5: 43-48; Lucas, 6: 2736; Génesis, 1: 26). Para Savater y Ferry los derechos humanos provienen de la cultura cristiana pero su formación y promulgación son una realización laica de la razón ilustrada. (como se citó en Leuridan, 2018, p. 167)

No obstante, Nietzsche nos hará ver cómo los grandes ideales surgidos durante la modernidad se van a revertir contra el hombre. La sola razón, no es ni será suficiente para explicar el gran misterio o interrogante que es la humanidad en sí misma. De esta forma, la filosofía abandona el cobijo de la razón y pasa a la negación de todo, incluso de sí misma, se pasa de la filosofía como madre de todas las ciencias a cuestionar el propio estatus de la filosofía como ciencia. Será lo que vaticinó A. Comte, el triunfo del positivismo, o el imperio de una forma de empirismo y pragmatismo filosófico. Si en un punto de la historia se podía decir que la filosofía era la esclava de la teología, ahora son las ciencias las que lo explican todo. 


\section{La cultura de la vulgaridad: la época posmoderna}

Nuestro punto de partida luego de esta incursión histórica no puede ser otro que lo que Johan Leuridan y Javier Gomá han llamado cultura de la vulgaridad. Por medio de la obra de Leuridan (2018) vemos que se describe nuestro mundo, nuestra época como posmoderna. Nuestro autor expone que esta crisis de valores tiene un mismo origen: «Los múltiples problemas a todo nivel se originan en una mentalidad común. Mis lecturas me convencieron de que el tema más cuestionado en el mundo posmoderno es la ética, o sea, el desconocimiento de la dignidad del hombre» (Leuridan, 2018, p. 8).

Este desconocimiento es señalado en su obra por medio de diferentes autores y filósofos como Javier Gomá, Savater o Luc Ferry, entre otros. A la vez que nos muestra cómo se manifiesta ese factor común que describe y colorea nuestra realidad. En la primera parte de su obra destaca algunos rasgos de nuestra época.

\section{El individualismo o triunfo del Yo}

Según el diccionario de filosofía de José Ferrater Mora, el término individualismo designa una doctrina según la cual el individuo -en cuanto «individuo humano»- constituye el fundamento de toda ley (Ferrater, 1964). Por su parte, Leuridan recurre a tres autores para enmarcar esta postura del hombre actual:

- Gilles Lipovestki. Para este autor nuestra época es la del triunfo del individualismo:

Vivimos en la era del individualismo más puro y de la búsqueda de la buena vida, limitada solamente por la exigencia de la tolerancia (siempre y cuando vaya acompañada de un individualismo autocelebratorio y sin escrúpulos, la tolerancia solo puede expresarse como indiferencia). La ética «posterior al deber» admite apenas un vestigio de moralidad, una moralidad «minimalista». (como se citó en Leuridan, 2018, p. 16)

Su tesis central es que el hombre posmoderno ha superado las ataduras de la moral y de la ética. A tal punto que ahora sí es plenamente libre. En un 
diálogo entre el Premio Nobel de Literatura, el peruano M. Vargas Llosa, y Gilles Lipovestki, con ocasión de la publicación de la obra: La civilización del espectáculo (Instituto Cervantes, 2019). Vargas Llosa, le imputó a Gilles asumir una postura en donde la principal búsqueda del ser humano es el placer y en este sentido ve esto como positivo, sin pensar más en el asunto, pero deja de lado la realidad de lo que ha llamado alta cultura, o cultura que está sujeta a la realidad de lo que denomina civilización del espectáculo. Este mundo o cultura desdeóntica se manifiesta como positiva para el ser humano.

- Javier Gomá. Para este filósofo nuestra era se caracteriza por el triunfo de la cultura de la vulgaridad. En donde el yo lucha por su originalidad y no se deja asimilar en un proyecto común, más allá de sus propios intereses. Nos indica que este nuevo ser humano grita libertad, pero no desea hacer un uso civilizado de la misma. El origen de esta falta de responsabilidad reside, según el autor, en que es una libertad que el hombre y la mujer de hoy se han encontrado pero que no han laborado para ella. Será por eso que no la sienten como suya y cuestionan todo. Gomá señala:

Basta abrir los ojos para contemplar el espectáculo de una liberación masiva de individualidades no emancipadas que ha redundado últimamente en el fenómeno original de nuestro tiempo: la vulgaridad. «Llamo vulgaridad a la categoría que otorga valor cultural a la libre manifestación de la espontaneidad estéticoinstintiva del yo». (como se citó en Leuridan, 2018, pp. 11-12)

Todos luchan por ser auténticos y originales en un mundo en donde lo que importa es solo lo externo, y la propia belleza se ha vaciado de contenido. El Yo se busca a sí mismo, sin ninguna garantía de poder hallarse. Es una búsqueda sin sentido.

Lo que caracteriza más profundamente a la vulgaridad actual es, desde luego, el sentimiento de igualación de cada miembro dentro de la masa, todos idénticos en su pretensión de ser únicos. Todos se tutean porque se imaginan del mismo nivel de inteligencia, responsabilidad y méritos. Hoy solo somos capaces de ver, en el espacio exterior, una monótona inmensidad de materia inerte, y en lo íntimo de la psique humana 
perversos instintos y pulsiones destructivas. La sociedad es una multitud de solos. (como se cito en Leuridan, 2018, p. 30)

- Peter Sloterdjik. Este filósofo alemán sostiene que para poder entender los cambios y nuestra propia cultura debemos recurrir al término bárbaro:

Es una fatalidad que sea el término «bárbaro» el que nos suministre la contraseña que nos franquea el acceso a los archivos del siglo XX. Esta expresión designaría al despreciador del rendimiento, al vándalo, al negador del status, al iconoclasta, al rechazador de todo tipo de reglas de ranking y jerarquía. Quien quiere entender el siglo XX no ha de perder nunca de vista este factor de la barbarie. Fue y ha seguido siendo algo típico de tiempos modernos recientes admitir ante el gran público la existencia de una alianza entre la barbarie y el éxito; al principio más bajo la forma de un imperialismo tramposo, hoy en día tras los disfraces de una vulgaridad invasiva, que, vehiculada a través de la cultura popular, se adentra en casi todos los campos. (Sloterdijk, 2013, p. 28)

Si hacemos memoria este término fue usado por los romanos para enmarcar a aquellos provenientes de culturas ajenas a la suya. Según el Diccionario de la Lengua Española, la palabra bárbaro, proviene del latín barbarus $^{1}$, voz de origen onomatopéyico a partir del sonido bar. En efecto, este pensador indica que actualmente esas conductas o formas de ser que podrían pasar en cierta época por extrañas o forasteras, se han hecho con la realidad y se vuelven comunes.

\section{La sociedad amoral y la malignización de lo bueno}

Continuando con su tesis Leuridan nos indica, de acuerdo a los filósofos Odo Maquard, Luc Ferry y Peter Sloterdijk, dos rasgos más que se han hecho típicos de nuestra cultura hodierna.

Voz: bárbaro en Real Academia Española, 2001. Diccionario de la Lengua Española (22ª ed.). 


\section{La malignización de lo bueno}

Odo Maquard, filósofo alemán, insiste en que hoy en día los términos bueno a malo, han perdido su real sentido:

Lo que antes era bueno ahora es malo. Hay una malignización de lo bueno tradicional. Nada válido, auténtico, verdadero se libra de la sospecha de no serlo: la economía aliena al hombre, el Estado es diabólico, la familia tortura y deforma a los jóvenes, la razón es la «opositora del pensamiento», el espíritu el «oponente del alma», la tolerancia, represión, la religión, embaucamiento, etc. La desmalignización del mal se hizo luchando contra la resistencia que oponían las valoraciones tradicionales. El mal se hace bien en la misma medida en que el bien es desenmascarado como mal [...] Lo que estamos describiendo es una tendencia «anti-moderna» del propio pensamiento moderno. La forma actual del antimodernismo no es más que la recaída -filosófico-revolucionaria- en la negación escatológica del mundo. Allí donde el antimodernismo tiene éxito, comienza el fin de la modernidad. (como se citó en Leuridan, 2018, p. 32)

En clases siempre trato de ilustrar esta tesis con algunos ejemplos sencillos. Qué pasaría si al pagar el micro (forma coloquial de llamar transporte urbano en Lima, Perú) el cobrador te devuelve dinero de más. Te lo quedas o le avisas al cobrador que te ha dado una cantidad que no es la justa. Algunos de mis alumnos afirman que siendo un acto de justicia divina. Lo mejor sería dejar las cosas así. Es decir, me quedo el dinero. Otro ejemplo, si el profesor al corregir tu examen de fin de curso, por error te califica con 17, y cuando tu revisas te das cuenta que tu nota es 11, ¿Qué harías? Según esta tesis, lo «correcto» seria callar. Además, allá el profesor, es él el que se ha equivocado no tú. Otro ejemplo, si por esas cosas de la vida, te «encuentras» un celular de última generación olvidado en el aula, conectado y cargándose. Para qué devolverlo. Piensas, además su dueño no lo merece, pues lo ha dejado olvidado y tirado ahí solito. Lo ideal o práctico no sería guardarlo y cuidarlo tú. Por otro lado, te lo has encontrado. Según este autor, actuar de esta forma, es decir, callar o dejar las cosas pasar, parece ser lo bueno o normal hoy en día. Es más, si tratas 
de hacer lo que debería ser, es decir, devolver el dinero de más, informar al profesor su error, o dejar el celular en objetos perdidos, y tratas de buscar consejo en tus «amigos», lo más seguro es que digan que si haces eso eres tonto, pues ya nadie lo hace. Pero lo peor es que aun haciendo lo debido tengas como cierto remordimiento: «me lo pude quedar», «nadie se enteraría», etc. Es como si hacer lo bueno hoy en día no estuviera de moda.

\section{La amoralidad de nuestra cultura}

Recuerdo que el profesor Sergio Belardinelli, mientras estábamos en clases, en el Giovanni Paolo II, en Roma, nos hablaba de la normal anormalidad. Es decir, es normal perder horas atrapado en el tráfico de Lima, lo anormal es que a hora pico tú te dirijas a casa o trabajo rápido por las calles de Lima. Luc Ferry, va más allá, al analizar este dilema posmoderno. No solo lo anormal se hecho la norma, sino que, para el filósofo francés, más que hablar de una conducta inmoral, nuestro mundo se ha hecho cada vez más amoral.

Con un ejemplo sencillo se puede entender la diferencia. Una persona inmoral sabe qué cosa está bien y qué está mal y aun sabiendo esto, hace lo malo, por ejemplo, la acción de fumar, sabemos, y la ciencia afirma que hace mal a la salud, pero como dicen los fumadores: que rico es fumar, es decir, hago lo malo.

Un amoral, no entiende o ve una diferencia entre bien o mal, para él son lo mismo. Un niño que apenas está enterándose de la vida (de 2 o 3 años), aún no sabe distinguir esta realidad. El infante no tiene noción real de la moralidad de sus actos. En ese sentido su mundo se hace amoral.

Recuerdo que, en clases, algunos compañeros en Roma, hablaron al tocar este tema de la amoralidad, de los zíngaros o gitanos, para ellos era difícil hacer labor social con ellos e impedir que cometan hurtos, ya que en sus costumbres el robar no era un tema moral. Ellos no lo veían como algo malo en sí, era solo cuestión de demostrar que los otros eran demasiado lentos, o tontos, no eran vivos como ellos. 
La amoralidad de nuestra cultura queda manifiesta en esa pérdida de sentido ante el reconocimiento del valor de dignidad de la persona humana, de la que nos habla Leuridan. Es notable como este autor, señala que allí radica el problema de nuestra sociedad actual. Recuerdo un caso para este punto. Una familia amiga tenía a su abuela hospitalizada, y se estaban turnando entre familiares para estar con ella día y noche. Cuando llegó el turno de la única nieta, una adolescente de unos 25 años, esta se excusó diciendo que no se podía quedar pues debía quedarse a cuidar a su mascota. Lo cual, es cierto, había sufrido un accidente. Al padre de ella le pareció bien y aunque ya había cumplido su turno, y le tocaba trabajar al día siguiente, decidió quedarse. Antes de seguir, debo confesar que yo también tengo mascota, y no soy un buen modelo para decir que no la engrío. Pero sé que es un animal, y aunque le conceda muchos derechos, hay prioridades. Mis padres vienen del campo, y me enseñaron a cuidarlas y protegerlas, pero también, a usar de ellas si fuera necesario. En el caso de mi amigo, creo que lo de a quién cuidar no era para ponerse en una misma balanza. Me lo imagino así, imi abuela o mi mascota?, ya el solo hecho de poner como si fuesen dos realidades idénticas nos hace ver que algo está pasando. No me mal entiendan, repito que también soy amante de los animales, pero por algo el animal racional es el hombre. Sin esa racionalidad y libertad, solo nos queda la animalidad. Pero como lo comento en clases, estos dilemas no solo nos pasan con los animales.

Sucede que muchos de nosotros padres, afirmamos que trabajamos duro por nuestras familias, por la economía y bienestar de nuestros hijos e hijas. Pero qué sucede cuando tu hijo o hija, te necesita, quiere conversar contigo, o solo estar o sentirse al lado tuyo, y le respondes que no puedes, pues debes ir a trabajar. Es como si la balanza estuviera así: ¿mi hijo(a) o mi trabajo?, cuántas veces no se ha inclinado esa balanza hacia el trabajo.

Pareciera que nuestro mundo hubiese perdido el sentido del valor humano. Lo humano en nombre de nuestra materialidad, se ha hecho una materia más, parte de nuestro intercambio diario. Kant, hablaba del hombre o de la humanidad como fin de toda acción humana, o lo que él llamó reino de los fines. Pero lo que ha llegado es que cada ciencia, cada acción se ha hecho un fin en sí misma y la humanidad del ser humano solo es una pieza más y no la fundante. En otras palabras, ya no se sabe que es la moralidad, que 
es el bien o el mal. Nuestra sociedad se ha vuelto en cierto sentido escéptica al hablar de valores. Pero lo anecdótico es que siempre habla de ellos: familia, amor, dignidad, etc. forman parte de nuestro vocabulario común, pero parafraseando a MacIntyre (2001) son palabras vacías, o fragmentos que nos han quedado de saberes anteriores, que hoy usamos, pero nadie o cada uno entiende a su manera.

\section{El emotivismo}

David Hume (1711-1776), filósofo escocés entre otras profesiones y artes, es a quien debemos recurrir para tratar de entender esta otra característica de nuestro mundo actual. Desde una perspectiva moral, Blázques, Devesa y Cano, (2002) nos dicen que «con la expresión de emotivismo moral se designa la concepción ética de Hume, según el cual lo bueno o lo malo depende de los sentimientos». Tenemos que reconocer que Hume es un empirista radical como bien lo señala Leuridan:

Omite la ley natural para dar paso al hedonismo, posibilidad ya señalada por Locke, abriendo el camino hacia un empirismo moral, político y económico. El empirismo entiende la relación del hombre con el ambiente por medio de las pasiones. La razón es solo un reflejo de estas. El hombre está sometido a las pasiones y por lo tanto el motivo de su ser es la utilidad. La ley no puede ser fuente de obligación porque la obligación presupone la utilidad. Reducir al hombre a una «experiencia» de pasiones y utilidad es el método experimental. Él descubre las reglas o leyes por una reflexión sobre los límites útiles de sus pasiones con los demás. Las leyes son un reflejo artificial de las pasiones. (como se cito en Leuridan, 2018, pp. 107-108)

En su libro Tras la Virtud, MacIntyre (1984), hace un intenso análisis del porqué para él nuestra época en el fondo es profundamente emotivista. La realidad y las emociones han dejado de estar comunicadas, ya no es la razón la que explica o ayuda al hombre a entender lo real. Sobre este tema, Leuridan (2018) afirma:

En lugar de ver el sentimiento como parte de una relación que tengo con el mundo, se entiende esta relación en función de lo que yo siento. 
De esta manera una experiencia de sinsentido, frustración o indignación ya no se entiende a partir de una situación con estas características, sino que se la reduce a una afección que necesita un tratamiento. Se quita el contenido a las emociones y se las considera como objetos mentales. Se pretende hablar sobre las emociones en términos terapéuticos. El sentimentalismo predomina en la vida. Por el acercamiento a las emociones como objetos naturales se construye un objeto que está fuera de su contexto cultural, negando la realidad de la comunidad humana como su verdadera realidad. (p. 35)

Es interesante ver que este nuevo hombre, esta nueva mujer, posmodernos, están preocupados siempre por su «bien-estar», de esta forma ya no se habla más de bien o mal, sino del bienestar de la persona. Pero no solo es un predominio de los sentimientos y las emociones fuertes. Sucede algo paradójico, el sentirse mal se vuelve algo malo. Al punto que, como lo señalo en clases, surge toda una tendencia contra el sufrimiento como tal. No me mal entiendan, no digo que esté bien vivir el sufrimiento. A lo que me refiero es que en nuestra época el sufrimiento pierde su realidad y no encuentra sentido. Pues el ideal actual es la felicidad, pero una felicidad no en términos aristotélicos sino inmediata. De esta forma todo sufrimiento queda vetado. No es casualidad que haya sendos debates televisivos en países desarrollados, en donde se supone que la calidad de vida ha mejorado, sobre si es o no licito aplicar la eutanasia, o abortos exprés, todo con el fin de que esos seres humanos no sufran una vida indecorosa o de dolor.

\section{Los líderes y la ejemplaridad}

Para todos es sabido que el ser humano como tal forma su personalidad en confrontación con otros seres humanos. Esto es uno de los ejes fundamentales que propone la teoría del psicoanálisis. El mismo Aristóteles lo había ya señalado en su pensamiento cuando nos hablaba de la virtud, no como algo innato, sino aprendido, adquirido como fruto de la razón y de la libertad humana. Leuridan (2018), nos dice:

La virtud no es una acción sino una actitud o postura relacionada con una elección. Esta actitud no se hereda, sino que se forma por esfuerzo de uno mismo o por influencia de los otros. El fin de la ética, a diferencia 
de otras tendencias, es mantener una tendencia al bien como elección. La virtud no es natural. La virtud, siendo la condición necesaria para actualizar la tendencia definida del hombre, no es una tendencia. (p. 44)

Savater (2004), filósofo español nos señala que el hombre -es su naturaleza- vive del arte de copiar de los demás:

Una de las características principales de todos los humanos es nuestra capacidad de imitación. La mayor parte de nuestro comportamiento y de nuestros gustos la copiamos de los demás. Por eso somos tan educables y vamos aprendiendo sin cesar los logros que conquistaron otras personas en tiempos pasados o latitudes remotas. En todo lo que llamamos «civilización», "cultura», etc. hay un poco de invención y muchísimo de imitación. Si no fuésemos tan copiones, constantemente cada hombre debería empezar desde cero. Por eso es tan importante el ejemplo que damos a nuestros congéneres sociales. (Savater, 2004, pp. 120-121)

Es en este punto donde siempre entra en debate el tema del líder. Debemos indicar qué es o quién es un líder. El Diccionario de la Lengua Española nos dice que un líder es una persona que dirige o conduce un partido político, un grupo social $u$ otra colectividad. Mientras que por el termino ejemplo se señala: Acción o conducta que puede inclinar a otros a que la imiten. En efecto, un líder podríamos decir que es aquel cuya conducta se manifiesta de forma ejemplar para otro. De tal forma que en los primeros años de vida, de casi todos los seres humanos, son nuestros padres esos modelos o ejemplos desde los cuales el nuevo ciudadano, el nuevo hombre o mujer formará su personalidad.

En una breve entrevista que se le realizó al filósofo español Javier Gomá, en Telemadrid, con ocasión de la publicación de su obra: Ejemplaridad Publica; este nos relata como el ser ejemplo es parte de cotidianidad del ser humano, de su devenir (Gomá, 2009). Somos ejemplos nos guste o no cada día ante los otros. Leuridan se refiere al pensamiento de Savater, Umberto Eco y otros, para demostrar cómo el ser humano se forma ante los ejemplos y los valores que evidencian quienes les rodea. 
En ese sentido, será la familia, la primera institución en la cual se forjan o esbozan, los valores de la persona. Pero, y como bien lo destacan mis alumnos, cada vez que vemos el tema de la ejemplaridad hay también malos ejemplos, y pareciera que, en nuestro mundo, en nuestro Perú, esos ejemplos cunden por todas partes, al punto que unos cuantos arboles no nos dejan ver la inmensidad del bosque.

Lo primero que siempre debemos afirmar es que es cierto que nuestros «líderes», tanto culturales como del Estado, así como lo señala muy bien Leuridan, forman parte de esta cultura posmoderna actual. Ellos no la han fundado, pero forman una parte integral de la misma. Son parte de este irrespeto por la norma: anomia, que todos viven. En esta cultura de la vulgaridad y del individualismo, los actuales líderes impuestos por el poder dominante o por la moda y los medios, solo son un fiel reflejo de nuestra cultura posmoderna. Si deseamos ver el bosque, como bien lo señala Gomá y el propio Leuridan, debemos volver a una cultura fundada en valores. Para esto quizás debamos comenzar, no por el otro sino por reformar nuestras propias costumbres, hasta que estas reflejen los valores que realmente vivimos. Recuerden que si no actuamos como pensamos, terminaremos pensando como actuamos. De que nos sirve decir que creemos en los valores, si estos no se evidencian en nuestras vidas.

Es así como la ejemplaridad y los líderes se vuelven parte característica de nuestra cultura posmoderna, quisiéramos que fuera de una manera positiva, pero la realidad es que ellos replican y sustentan el mundo de hoy: anómico y amoral.

En este punto, hay que destacar lo que ya afirmaba Aristóteles, cada uno es responsable de sus actos, sería fácil como dicen algunos culpar a los medios, las circunstancias, o hasta a nuestros propios padres por las cosas que hacemos o el destino que tenemos, pero la verdad, es que si el hombre de hoy se funda sobre la libertad, fue en nombre de esa libertad que tú y yo elegimos hacer lo que hacemos. Por buenos o malos padres que hayamos tenido, no importa si nacimos en la periferia o en una gran urbanización, lo que nos define como buena o mala persona son las elecciones que hacemos. Estas, a su vez, se basan en aquellos criterios que en nuestra primera infancia elegimos como directrices de nuestras vidas. Podemos renegar y echar la culpa al líder, pero la verdad 
es que nosotros le dimos ese lugar de liderazgo, y además nos es muy cómodo seguirlo.

\section{Tecnocracia y competitividad}

Al final casi del análisis de este primer contacto con nuestra realidad, no podemos dejar de señalar el poder de la ciencia o lo que Leuridan llama la razón tecnológica o causalidad mecánica y el poder del mundo globalizado y la competencia industrializada. Hace años atrás mientras leía las tesis del que en su momento fue considerado un futurólogo de nuestros tiempos, a saber, Alvin Toffler (1980), en su obra más famosa, la Tercera Ola, tropecé con aquella odiosa comparación entre el sistema escolar y las empresas. Para él, nuestro sistema educativo occidental estaba hecho, no para forjar libre pensadores y hombres y mujeres libres, no, su función era preparar al obrero calificado, usando una especie de conductismo educativo. De tal forma y como bien lo cantaba Pink Floyd, la banda británica de rock, nuestros alumnos no eran más que un ladrillo en la pared. Hoy todo el mundo habla de empoderar al joven, al pobre, etc. Pero pareciera que lo único realmente empoderado es el mercado y las empresas transnacionales. Las cuales, con su sistema económico y sus grandes centros de investigación controlan la economía mundial.

Los mass media no escapan a esta realidad, el sociólogo francés Dominique Wolton (como se cito en Leuridan, 2018), dirá que hoy, que pareciera que la tecnología ha facilitado su trabajo a los medios de comunicación, y que deberíamos estar más comunicados, pasa lo contrario. La tesis es sencilla y aclara la situación. «El ser humano se comunica, las maquinas se conectan». Lo esencial de la comunicación no es de tipo tecnológico sino antropológico y cultural (p. 43). Como bien lo indica Luridan (2018):

Los resultados prácticos de la ciencia y de la tecnología prescriben el orden político, ético y jurídico. El positivismo predominante del mundo científico deshumaniza a las personas. Ya no se busca un consenso sobre lo verdadero, lo justo y lo bello sino el principio más eficiente. La ciencia se vuelve pragmática.

Es decir, pasamos de la ciencia como medio para una buena vida a la ciencia como un fin en sí misma. Según la filosofía analítica es la propia ciencia 
la que determina la felicidad del hombre y, por supuesto, esta no está en entes metafísicos sino dentro de la propia naturaleza humana, en su materialidad.

Leuridan, menciona al filósofo francés Luc Ferry y a Ralf Darendorf, intelectual liberal, germano británico, para reforzar esta tesis; al respecto dirá que ellos «consideran que las elites dominantes y la competitividad generalizada entre empresas transnacionales, con sus laboratorios de investigación científica, ha impuesto la ley de competitividad de producción y consumo, eliminando todo sentido, valor o finalidad» (como se citó en Leuridan, 2018, p. 40).

Creo que el ejemplo usado en clases de moral nos puede evidenciar el peligro del gobierno de los especialistas de la tecnocracia y su poder. Se cuenta que, durante la Segunda Guerra Mundial, en la cual se usaron las famosas cámaras de gases para matar y torturar al pueblo judío, se les presentó a los verdugos un problema técnico. Cuando introducían a los reos en la cámara para ajusticiarlo, resulta que algunos después de ser rociados con el gas permanecían aún con vida, y debían terminar usando balas para ajusticiarlos. Esto implicaba un gasto incrementado de material (balas y gas), algo costoso en tiempos de guerra. Llamaron a un especialista para verificar y dar una solución al «problema técnico».

Al revisar, el especialista, las dimensiones de la cámara, vio la cantidad de detenidos y se dio cuenta que estaba correcta según sus cálculos, y los de sus técnicos y diseñadores. Luego se percató, de que era un tema de resistencia del cuerpo humano -cosa rara, algunos humanos nos resistimos a morir- y tenían más aguante ante la inhalación del gas letal. Pero el mismo técnico notó otro hecho: cerca de la cámara letal había un campo de fútbol. Su idea fue que los reos corran hasta el cansancio en el campo y luego pasen a la cámara. Con lo cual la resistencia sería poca. Al parecer así se hizo y el resultado fue el esperado. Como se ve este hecho describe como la técnica puede ser usada de manera inhumana, eso sí en nombre de la humanidad. Esto recuerda a la teoría muy usada hoy por muchos moralistas del utilitarismo. Lo bueno es aquello que me es útil, el problema es que lo útil no siempre es lo mismo para todos. 
Ferry (2016) nos muestra, por medio de su obra la Revolución Transhumanista, hasta dónde el poder de las ciencias está transformando no solo el mundo sino la propia naturaleza humana. Su obra pareciera ser el grito del centinela que anuncia la llegada de un peligro. Peligro que no todos vislumbran, más bien pareciera que algunos lo atesoran como algo inevitable y hasta «natural», es un paso más de la evolución humana.

En síntesis, estas primeras páginas nos muestran cual es la realidad del hombre y de la mujer de hoy desde el punto de vista ético-filosófico. Una realidad donde prima el relativismo y el emotivismo como postura moral. Donde la ciencia o la técnica tiene la última palabra sobre la humanidad. Pero no todo es «novela negra» sobre la humanidad, ya que la ética y la filosofía han abierto paso a un ser humano que aún busca respuestas sobre sí mismo y sobre su humanidad. En este sentido, recurriremos con Leuridan a los grandes filósofos de la historia para presentar una propuesta ética basada en la virtud del amor, como respuesta a las interrogantes actuales del ser humano.

\section{La ética de la virtud: un humanismo del amor}

En un primer momento, cuando trato de explicar en qué consiste la propuesta de la ética desarrollada por el Dr. Johan Leuridan, desde nuestra casa de estudio, la Facultad de Ciencias de la Comunicación, Turismo y Psicología de la Universidad de San Martín de Porres, y les digo a mis alumnos que la respuesta es el amor, la mayoría me ve con rostro de incredulidad. Cuando afirmo, que es el amor y no otra nuestra propuesta ética al comienzo nadie nos cree. Pero eso es lo mismo que les voy a decir a ustedes lectores.

Quiero iniciar este análisis citando al propio Santo Tomás de Aquino:

Se dice que la caridad es forma de todas las virtudes, ya que incluso las mismas virtudes son tales por el ordenamiento a los actos formados, $[\ldots]$ En cuanto les impone a todas las virtudes forma y el modo, [...] porque en ella (la caridad) se sustentan y de ella se nutren las demás virtudes. (Aquino, 1986, II, q 23, a 8)

En un mundo donde impera el individualismo como forma cultural y de comportamiento cotidiano, el renacer de la ética, no es una mera casualidad o moda pasajera. Habermas, Luc Ferry, Fernando Savater, Peter Sloterdijk, 
Hans Kung, todos ellos, tienen un factor en común en el entramado de nuestro análisis. Todos claman por la ética. Es aquí donde nos debemos detener a reflexionar. Cabe hacer una primera pregunta ¿por qué?, qué tiene la ética y sobre todo la filosofía que aportar a un mundo basado en la ciencia.

Si recordamos nuestra época posmoderna, tiene como base la crítica nihilista que el filósofo Nietzsche ha realizado a todo el pensamiento moderno. Un pensamiento cuyo axial es el triunfo del yo, de la razón frente al mundo, la realidad y el otro. La sola razón, mejor dicho, mí sola razón basta para entender la complejidad del mundo, del otro y mi ser. En su obra, Gaya ciencia, Nietzsche (1990) pone en boca del loco las siguientes líneas:

¿Dónde está Dios? - , [...] iNosotros lo hemos matado, ustedes y yo! iTodos somos unos asesinos! Pero, ¿cómo lo hemos hecho? ¿Cómo hemos podido vaciar el mar? ¿Quién nos ha dado la esponja para borrar completamente el horizonte? [...] iDios ha muerto! iDios está muerto! iY lo hemos matado nosotros! ¿Cómo vamos a consolamos los asesinos de los asesinos? [...] ¿No tendríamos que convertimos en dioses para resultar dignos de semejante acción? Nunca hubo un hecho mayor, iy todo el que nazca después de nosotros pertenecerá, en virtud de esta acción, a una historia superior a todo lo que la historia ha sido hasta ahora!

La pregunta que cae bajo su propio peso es quién o qué es este dios que muere. La respuesta es obvia, es el dios que da sentido a todo, o mejor dicho el dios de las grandes explicaciones racionales al problema del mundo, del hombre y de dios mismo. No se trata solo de una crítica vedada al dios cristiano, sino a la cultura humana de ese entonces, es decir, a la propia modernidad. Los nietzscheanos y entre ellos algunos de mis alumnos que asumen a este filósofo como su guía, cuando presento a este autor, señalan que esto no tiene nada de negativo. Al contrario, es un momento de posibilidad. El hombre, el ser humano ahora tiene su momento protagónico. Como si fuese un nuevo Prometeo ya no es cuestión de robar el fuego a los dioses, sino el momento de ser dios, o dejar a dios en su trono e iniciar una nueva humanidad, pues el ser humano (hombre y mujer) y solo él, tiene en sus manos la historia. 
Siempre uso la figura de un rompecabezas para responder y explicar este paso. El ser humano posmoderno no construye cultura, civilización o mundo. De hecho, Nietzsche hablaba de filosofar a martillazos, o lo que llamó Jean Derrida, «deconstrucción». Imaginen que, y volviendo a las etapas de la filosofía, en las tres primeras etapas el ser humano se venía armando pieza a pieza el rompecabezas de su propia realidad, de su cultura. Unos centrados en el «arje», otros en «Dios» y los últimos en la «ley y la razón». Pero ahora pasa lo que podríamos describir con el siguiente caso. Imaginemos, que, en casa, de manera familiar, hemos adquirido un gran rompecabezas, de unas cinco mil piezas. Iniciamos todos el armado. Pero por esas cosas de la vida, me llaman del trabajo y debo dejar de seguir armando. La regla es que nadie lo termine sino están los otros, pero sabemos que la confianza no es una virtud que esté muy de moda, además por qué parar. En ese momento, ieureka! a ti se te ocurre una gran idea. Llevarte una pieza, así, aunque ellos sigan construyendo no podrán terminarlo, y no solo eso, tú sabes, que tienes la pieza final, la que importa. Pero de la misma forma ha pasado con tu hermana, tu primo y tu papá. Cada uno se tuvo que ausentar como tú, y en este mundo donde manda la viveza, en términos peruanos: la criollada; parafraseando a Nietzsche: el superhombre; todos han hecho lo mismo, han ocultado una pieza. Es más, piensan todos que su pieza es la importante. Al final como vez nadie construye, sino que al contrario deconstruyen, y como si fuera peor, para todos su pieza es la importante. En términos de filosofía, su verdad, su idea.

Ahora se puede entender mejor la idea de la deconstrucción de Derrida y Nietzsche. Esto pasa en todos los campos, pero donde más se sufre es en el campo de la política. Recuerden que la política para Aristóteles es la ciencia de la «polis» y su razón de ser es buscar el bien para todos, de ahí que él insista en que la política y la ética van de la mano y se necesitan mutuamente. La buena vida no es solo buena vida para mí, debe ser una buena vida humana con los humanos: la polis o humanidad: nueva polis hodierna.

Sartre, nos muestra las consecuencias de tomar la muerte de Dios como fundamento de nuestra cultura actual:

El filósofo ateo Jean-Paul Sartre y el existencialismo critican a los filósofos de la modernidad que aceptaron la muerte de Dios con mucha ligereza. No se habían dado cuenta de las consecuencias de la negación de la 
existencia de Dios para poder construir una ética de la autonomía absoluta del hombre. Los valores se habían quedado sin ningún fundamento. No se dieron cuenta de que los valores tradicionales tienen su fundamento exclusivamente en Dios. Puesto que Dios no existe, afirma Sartre, el hombre está condenado a la libertad, una libertad sin normas. Si la historia no tiene una finalidad tampoco puede existir una moral que obliga. La felicidad de este hombre es nauseabunda. (como se citó en Leuridan, 2018, p. 183)

Debemos ahora, sin más preámbulo, responder a nuestra inquietud inicial, por qué la ética está de moda. Por qué nuestros autores tienen este enfoque común: la ética. Como la respuesta a la propia supervivencia de la humanidad, Leuridan destaca que este recurso, fue usar a la ética, como una primera respuesta a lo que sería un mundo o cultura sin ley. Es decir, frente a la cultura de la amoralidad, de la anomia y cuasi de forma kantiana, lo mejor era recurrir a las normas y a la ética, como un lugar común de normas para todos. De hecho, Luc Ferry afirma que son la ética kantiana y el utilitarismo, las éticas dominantes en el mundo de hoy. Por otro lado, recuerden que la ética es el arte de la buena vida; al parecer el hombre y la mujer de hoy tienen esta premisa de la buena vida como fundamento de su cultura de bienestar.

En esto se puede afirmar que no se equivocan. Hablar de ética es hablar de normas valores y principios válidos universalmente. Es aquí donde la ética, la moral y la propia filosofía surgen cual ave fénix de sus cenizas.

Al tratar de definir la ética, Aristóteles la pone junto a la política como una ciencia de la acción humana. El hombre, el ser humano busca y tiene como fin de obrar su «telos», la búsqueda de la felicidad. Pero esta es solo posible, si está orientada a la felicidad de todos, es decir, de la polis.

Leuridan nos sugiere que, para entender con profundidad a este filósofo y su ética de la virtud, hay que ver al ser humano, no solo dentro de la polis o como ser político, amistad y pertenencia que este aprende y que se generan a partir del núcleo familiar.

En su artículo sobre la reconstrucción de la civilización, Leuridan se refiere a Luc Ferry para hablar del amor y de la importancia del matrimonio y la 
familia en la formación del ciudadano y de la nueva civilización. Esto no es solo una idea de Leuridan o de Luc Ferry, además sabemos que ambos están en polos opuestos al tratar el tema de la trascendencia. Ambos filósofos coinciden en el tema del amor, sobre todo, en el peso que otorgan a la familia, como escuela y comunidad donde el ser humano comienza a desarrollar esa característica esencial de su ser como persona, su personalidad, su ciudadanía, en la alteridad familiar. No hay distinción entre vida pública y privada como quieren algunos. Monique Canto-Sperber señala:

Aristóteles no piensa en dos formas de vida con igual valor, como algunos modernos quieren interpretar. Existe un fin excelente en la vida que vale para todos: la virtud moral no puede florecer en diferentes áreas de la vida social. No existen diferentes formas de vida moral. (como se citó en Leuridan, 2018, p. 209)

El análisis que hace Leuridan de la obra de Aristóteles no solo destaca que este tiene idea de bien como noción central de la ética. También, afirma que el ser humano posee la capacidad y dimensión ética para llegar a la verdad gracias a su razón y su libertad. Este ideal nace y se realiza en la sociedad, en la polis:

El ideal para una vida feliz es, para Aristóteles, un ideal de vida en comunidad y un ideal compartido por todos. El hombre tiene el deseo «por naturaleza» de formar una comunidad en la cual se cumpla su desarrollo. «Es cosa amable hacer el bien a uno solo; pero más bella y más divina es hacerlo al pueblo y a las ciudades. (Leuridan, 2018, p. 61)

Desde este punto de partida, y sin temor a equívocos, se debe afirmar que el inicio de la vida virtuosa se da en el ser humano por medio de ese bagaje cultural que se genera en la familia. Es ahí donde el ser humano aprende a amar y ser amado. Luc Ferry, lo expresa de forma clara cuando analizando su propia experiencia descubre la trascendencia del amor:

He descubierto entonces lo que descubren todos los padres, es decir que un niño despierta en vosotros sentimientos extraños diferentes de otras formas de amor, aunque sean tan fuertes, apasionados y auténticos. Dios sabe, sin embargo, si he podido amar en mi vida [...] Pero este amor, 
que en la singularidad de cada niño nuevo no se divisa, sino se multiplica de una manera tan extraña, surge de otra esfera: se trata de un amor que se parece a lo que los cristianos llaman agápç, amor gratuito, totalmente desinteresado porque "no es recíproco». (como se citó en Leuridan, 2018, p. 319)

Durante las clases me gusta hacer mención que siendo muchas las virtudes y los valores que se podrían rescatar para hablar de un refundar la ética hoy en día, Leuridan solo le da espacio de análisis único a dos de ellas, a saber, la justicia y el amor. Pero no deja de lado aquella virtud que fue llamada por los griegos la auriga virtutem, la prudencia o el conocimiento práctico.

Para Leuridan, así como para Aristóteles, la justicia es el arte del saber relacionarse con los demás. La razón de su ser no radica en un bien para uno mismo. Si nos fijamos, nadie, aunque se hiciese daño a sí mismo pensaría que lo hace de manera injusta. En su forma de pensar, lo que hace para sí es merecido. Mientras que al tratar a los demás tiene que orientarse a un bien que está más allá de sí mismo. De tal forma que la regla de oro se hace eco de este trato si deseo que este sea justo: trata a los demás como deseas ser tratado. Savater al hablar del trato dice que las relaciones entre humanos deben ser marcadas por ese adjetivo: humanas. En un mundo en donde el otro está como diluido, o como decía Zygmunt Bauman, en una modernidad líquida, lo sólido sería partir de la dignidad humana como único fundamento de nuestro actuar. La única virtud que hace referencia a ella de forma explícita es la virtud de la justicia; aquella de dar al otro lo que le corresponde, lo suyo. Sabiendo que este «lo suyo», forma parte de su realidad ontológica, de su ser: ser humano (Bauman, 2003).

La ética de la virtud como fundamento de este humanismo del amor, o de esta revolución del amor, nace de la virtud del amor, o del amor como la forma de todas las virtudes. Es decir, en nuestro mundo donde algunos han puesto una imagen catastrófica sobre la naturaleza humana se debe rescatar y valorizar lo que autores como Luc Ferry, Javier Gomá y el propio Leuridan refiriéndose a Sloterdijk ponen como eje del pensamiento actual: la cultura del don. 
El vínculo social primario es el don. Para Sloterdijk la generosidad existe en el hombre tanto como la codicia. La cohesión social se fundamenta en el don. Hay un fundamento neurológico para la capacidad de intuición y participación. No es una facultad de razonamiento sino la unión emocional con los demás. Tenemos que cambiar la imagen negativa promovida por las antropologías negras porque no corresponde a la vida de los que respetan los valores. (como se citó en Leuridan, 2018, p. 366)

Es el amor y no el temor de lo que está hecho el futuro de la humanidad, como signo de esperanza.

En síntesis, para forjar un esbozo de vida virtuosa se debe partir de rescatar y retomar esos valores y tradiciones que la humanidad siempre ha vivido. Como bien lo señala Hans Küng:

La nueva constelación política global no permite prescindir de ciertas categorías éticas. Para poder funcionar, el mundo no puede fundarse en un pluralismo arbitrario posmoderno. Debemos partir de lo que nos une y nos identifica como humanidad, el mismo autor se pregunta si estos no están contenidos en sentir o hecho religioso o lo que llama los fundamentos espirituales de la humanidad. (como se citó en Leuridan, 2018, p. 203)

En tal sentido, la respuesta al nihilismo de Nietzsche solo es posible desde la trascendencia, desde la realidad divina que nos revela la profunda inmensidad del misterio de lo que significa el ser humano.

Por su parte MacIntyre (1984) nos dice:

Si la tradición de las virtudes fue capaz de sobrevivir a los horrores de las edades oscuras pasadas, no estamos enteramente faltos de esperanza. Sin embargo, en nuestra época los bárbaros no esperan al otro lado de las fronteras, sino que llevan gobernándonos hace algún tiempo. Y nuestra falta de conciencia de ello constituye parte de nuestra difícil situación. No estamos esperando a Godot, sino a otro, sin duda muy diferente, a San Benito. (p. 322) 
En efecto, el ser humano debe tomar conciencia de su propio ser no en sentido negativo y de caos. No, más bien debe ser esperanzador. En nosotros está el retomar el camino de la virtud que nos revele la verdadera potencialidad del ser humano.

\section{Referencias}

Aquino, T. (1986). Summa Teologiae. Madrid: BAC.

Bauman, Z. (2003). Modernidad líquida. Ciudad de México: Fondo de Cultura Económica.

Blázques, F., Devesa, A., \& Cano, M. (2002). Diccionario de términos éticos. Navarra: Verbo Divino.

Ferrater, J. (1964). Diccionario de filosofía (5a ed.). Buenos Aires: Sudamericana.

Ferry, L. (2016). La Revolucion Transhumanista, como la tecnomedicina y la uberización del mundo van a transformar nuestras vidas. Madrid: Alianza Editorial S. A.

Gomá, J. (23 de setiembre de 2009). Ejemplaridad pública. Telemadrid [entrevista]. Recuperado de https:/l youtu.be/AhhYUfaxAJO[16/07/19]

Instituto Cervantes. (15 de marzo de 2019). Letras Libres. Alta cultura o cultura de las masas. Recuperado de https://www.letraslibres.com/mexico-espana/alta-cultura-0-cultura-masas

Leuridan, J. (2016). El sentido de las dimensiones éticas de la vida (1 ${ }^{\mathrm{a}} \mathrm{ed}$.). Lima: Fondo Editorial USMP.

Leuridan, J. (2018). El sentido de las dimensiones éticas de la vida (3a ed.). Lima: Fondo Editorial USMP.

Macintyre, A. (1984). Tras la virtud. Barcelona: Austral.

Nietzsche, F. (1990). La Gaya Ciencia. Caracas: Monte Avila Editores, C. A.

Sandel, M. (2012). Justicia ¿hacemos lo que debemos? Barcelona: Penguin Random House.

Savater, F. (2004). Ética para Amador. Barcelona: Ariel.

Sloterdijk, P. (2013). Has de cambiar tu vida. Valencia: Pre-Textos.

Toffler, A. (1980). La Tercera Ola. Barcelona: Plaza \& Janes Editores. 